\title{
Fat-free mass change to weight change ratio during refeeding following lung transplantation
}

\begin{abstract}
Malnutrition occurs frequently prior to lung transplantation (LTR), but patients gain weight after LTR. The study aimed to determine the ratio changes of fat-free mass $(\triangle \mathrm{FFM})$ : changes of body weight $(\triangle \mathrm{BW})$ during refeeding. $\mathrm{A}$ total of 37 LTR patients were measured for weight and FFM and body fat by bioimpedance analysis at 1 month post-LTR, then annually for 3 years. Linear regressions determined the ratio $\triangle \mathrm{FFM}: \triangle \mathrm{BW}$ during refeeding. $\triangle \mathrm{FFM}$ was: year$1=1.822+0.389^{*} \Delta \mathrm{BW}, r^{2}=0.397 ; \mathrm{yr}-2=0.611+0.246^{*} \Delta \mathrm{BW}$, $r^{2}=0.441 ; \mathrm{yr}-3=-0.17+0.208 * \Delta \mathrm{BW}, r^{2}=0.319$. Refeeding during year- 1 in thin subjects resulted in a ratio $\triangle F F M: \Delta B W$ of 0.389 , whereas the change in ratio $\Delta \mathrm{FFM}: \Delta \mathrm{BW}$ during year2 and 3 was 0.246 and 0.208 , respectively. Refeeding resulted in a larger ratio $\triangle F F M: \Delta B W$ in thin subjects versus normal and overweight subjects. Thus, refeeding in underweight LTR patients is geared to normalizing depleted FFM, whereas later FFM gains were similar to FFM gains in normal and overweight subjects.
\end{abstract}

Key words Bioelectrical impedance analysis (BIA) • Body composition $\cdot$ Fat-free mass $\cdot$ Body fat mass $\cdot$ Lung transplantation $\cdot$ Nutritional assessment

U.G. Kyle • C. Raguso • C. Pichard ( $₫)$

Clinical Nutrition, Geneva University Hospital, Switzerland

E-mail: claude.pichard@medecine.unige.ch

L. Nicod

Pneumology, Geneva University Hospital, Switzerland

D. Hans

Nuclear Medicine, Geneva University Hospital, Switzerland

\section{Introduction}

Lung transplant patients are often malnourished prior to lung transplantation (LTR), but gain weight rapidly after LTR. The etiology of weight loss in pulmonary disease is multifactorial and includes altered metabolism [1], presence of inflammatory mediators [2], and alterations produced by treatment and exacerbation of the disease [3]. Weight gain is common following heart [4] and liver transplant [5], however, no data are available in LTR patients. Although some weight gain is desirable, excessive gain in body fat should be avoided.

Refeeding after energy deprivation has been shown to increase fat-free mass (FFM) [6, 7]. Keys et al. [8] found a prompt regain in FFM and body fat after semi-starvation. However, few studies have evaluated the change in FFM to body weight changes (AFFM: $\triangle \mathrm{BW}$ ) in healthy subjects and none has reported these changes in LTR patients. The aim of this study was to determine the ratio $\Delta \mathrm{FFM}: \Delta \mathrm{BW}$ during refeeding following LTR.

\section{Subjects and methods}

Body composition was measured in 37 LTR patients at 1 month and 1, 2, and 3 years post-LTR. Thirty-seven healthy volunteers, matched for age ( \pm 2 years) and height $( \pm 2 \mathrm{~cm})$, were used as controls. Informed consent was obtained from subjects before being placed on the LTR waiting list.

Body height was measured to the nearest $0.5 \mathrm{~cm}$ and body weight was measured to the nearest $0.1 \mathrm{~kg}$ on a balance beam scale. Body composition was determined by $50 \mathrm{kHz}$ bioelectrical impedance analysis (BIA) as previously described [9] and validated $[10,11]$.

FFM was calculated using a previously validated multiple regression BIA equation [11]: FFM $=-4.104+\left(0.518 *\right.$ height $^{2} /$ resistance $)+$ $(0.231 *$ weight $)+(0.130 *$ reactance $)+[(4.229 * \operatorname{sex} \quad(m e n=1$, women=0)]. Cross-validation of BIA with DXA was excellent, 
$r=0.986, \mathrm{SEE}=1.72 \mathrm{~kg}$, technical error $1.74 \mathrm{~kg}$. This same BIA equation was also validated in elderly subjects [12] and transplant patients [13].

\section{Statistical analysis}

Descriptive statistics were calculated for height, weight, \% ideal body weight, BMI, and body composition parameters and are expressed as mean \pm standard deviation. Unpaired $t$ tests were used to test differences between pre-LTR and selected post-LTR measurements at 1 month and 1,2, and 3 years). Simple linear regressions were calculated between weight change and FFM change and body fat change. Statistical significance was set at $p<0.05$ for all tests.

\section{Results}

Patients had significantly lower weight and BMI at 1-month post-LTR evaluation than volunteers (data not shown). FFM was significantly lower throughout the study period in men and during the first year in women (Fig. 1). FFM was significantly higher at 1 year in women and 2 and 3 years post-
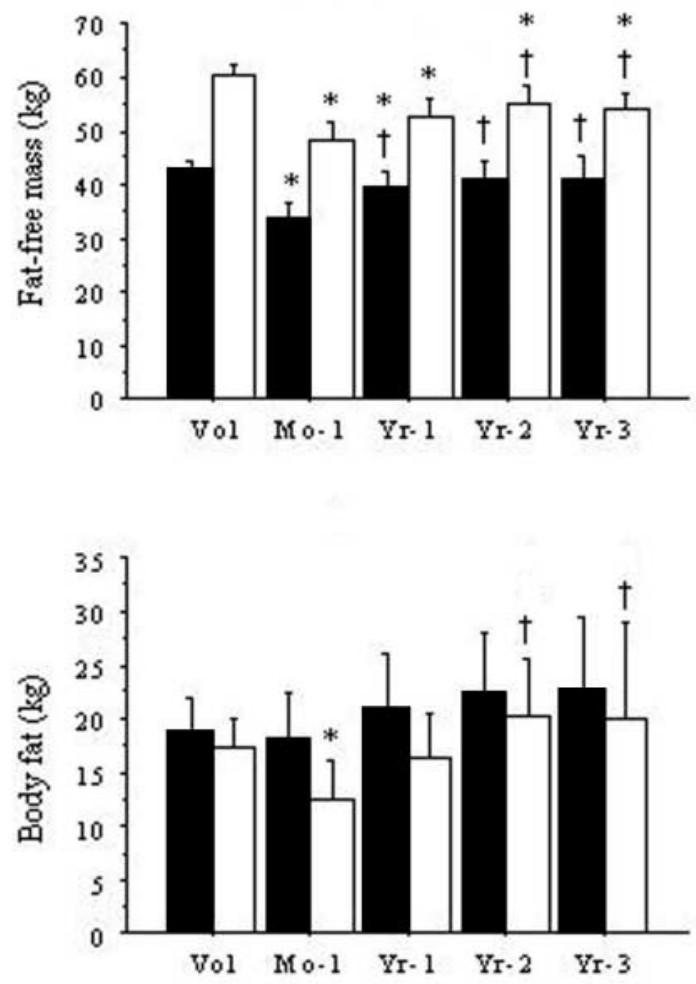

Fig. 1 Fat-free mass (top) and body fat (bottom) in $\mathrm{kg}$ in female and male $\square$ volunteers and patients at 1 month and 1,2, and 3 years. $* p<0.05$ vs. Vol; $\dagger p<0.05$ vs. Mo- 1
LTR in men and women than at 1 month (Fig. 1). BF was significantly lower at 1 month after LTR in male patients than in volunteers, and significantly higher at 2 and 3 years than after 1 month in men. The weight gain after LTR resulted in FFM and body fat gain.

Figure 2 shows the $\triangle F F M$ in comparison with $\triangle \mathrm{BW}$. The $\Delta F F M$ increased by $0.39,0.25$, and $0.21 \mathrm{~kg}$ for each kilogram of $\Delta \mathrm{BW}$ during years 1,2 and 3, respectively. The $\Delta$ FFM was higher ( $39 \%$ of weight) during year 1 than

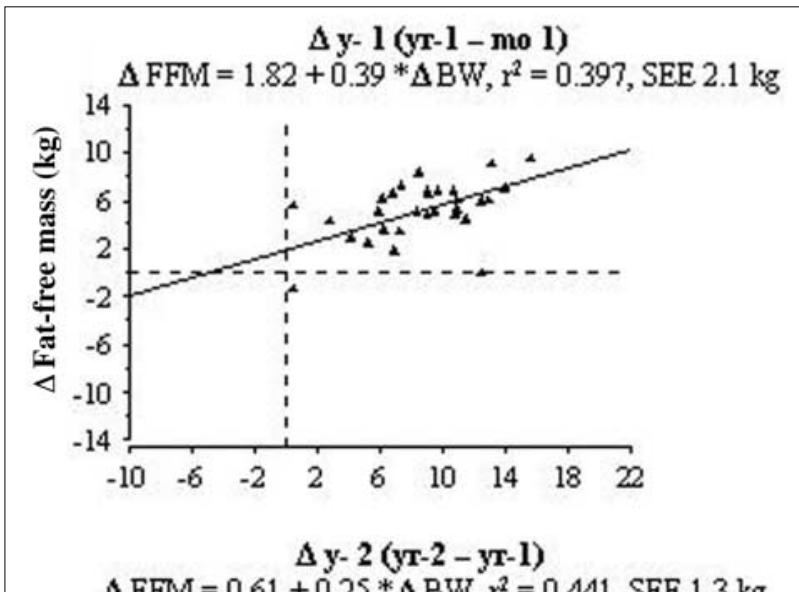

$\Delta \mathrm{FFM}=0.61+0.25 * \Delta \mathrm{BW}, \mathrm{r}^{2}=0.441, \mathrm{SEE} 1.3 \mathrm{~kg}$

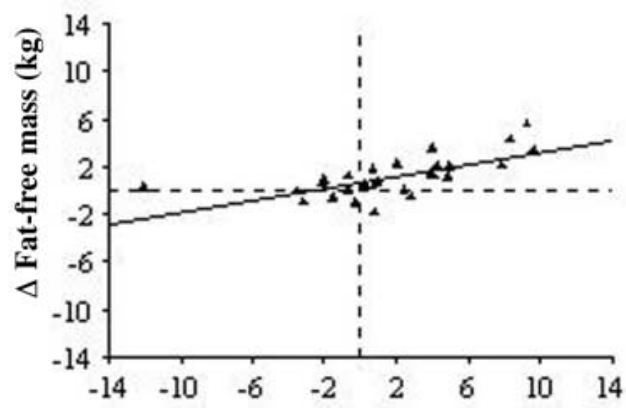

$\Delta \mathrm{y}-3(\mathrm{yr}-3-\mathrm{yr}-2)$

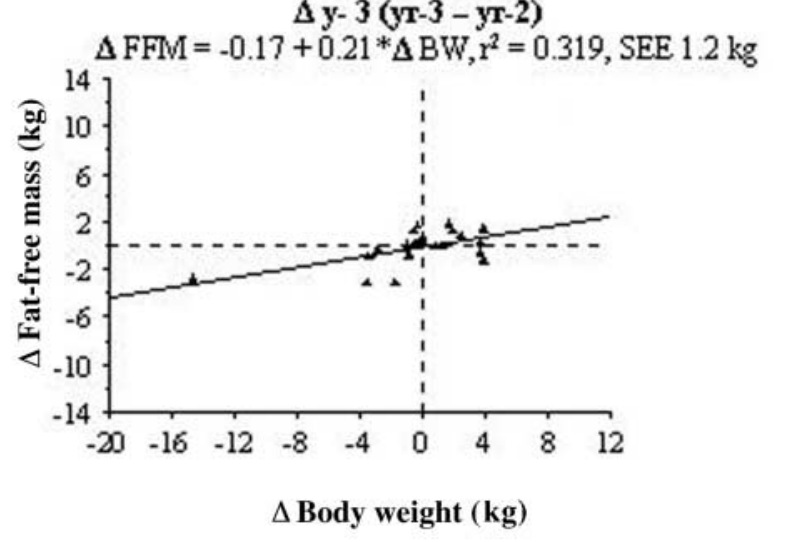

Fig. 2 Correlations between changes in body weight and $(\Delta \mathrm{BW})$ fat-free mass $(\triangle \mathrm{FFM})$ during year 1 (top), year 2 (middle), and year 3 (bottom). The respective FFM changes are expressed in relation to body weight changes. The FFM change was higher (39\% of weight) during year 1 than during year $2(25 \%)$ or year $3(21 \%)$ 
during year $2(25 \%)$ or year $3(21 \%)$. From these results we may deduce that an increase in weight resulted in an increase in FFM.

\section{Discussion}

The aim of this study was to determine the $\Delta F F M: \Delta B W$ during refeeding following LTR. Significant FFM increases were noted following LTR. Forbes [14] estimated the expected $\Delta F F M: \Delta B W$ to be 0.48 for thin subjects and 0.26 for moderately obese subjects. Linear regressions (Fig. 2) between $\triangle \mathrm{FFM}$ and $\triangle \mathrm{BW}$ in our subjects showed a change of 0.39 and $0.25 \mathrm{~kg}$ FFM per kg weight change during year 1 and year 2, respectively. Thus, the FFM increases following LTR were in the expected ranges of change noted during recovery from energy deprivation. FFM to weight gain rates were higher in the early versus later recovery period, whereas higher rates of body fat to weight change were noted during year 2 and year 3 compared to year 1 (data not shown).

Refeeding after energy deprivation has been shown to increase FFM in anorexia nervosa [6], voluntary semi-starvation [8], and physical training with energy deficit [7]. Keys et al. [8] found a prompt regain in FFM and body fat after semi-starvation. The accretion of body fat occurred more rapidly than FFM. Both the Ranger Study [7] and the Minnesota Starvation Study [8] showed that FFM also returned to baseline later in the recovery process. A return to normal body composition was also noted 12 months after surgery in ulcerative colitis patients who had undergone colon and ileal resections [15]. Our study shows that a return to baseline body composition is possible after energy deprivation and illness in spite of treatment, such as calcineurine inhibitors, steroids and other drugs that might interfere with cell metabolism. Further research is required to determine the magnitude and contribution of the FFM to body weight gain in subjects who are ill.

\section{Study limitations}

The measurment of BIA is occasionally criticized. In this study, simultaneous measurement by BIA and DXA showed a mean bias of $-0.4 \pm 1.5 \mathrm{~kg}$, range $-3.9-3.4 \mathrm{~kg}, r=0.987$, $\mathrm{SEE}=1.5 \mathrm{~kg}$. Therefore, there is good agreement between BIA and DXA.

\section{Conclusions}

Refeeding resulted in larger $\triangle \mathrm{FFM}: \triangle \mathrm{BW}$ in thin subjects than in normal and overweight subjects. Thus, it appears that refeeding in underweight transplant patients is geared to normalizing depleted FFM, whereas later FFM gains are similar to FFM gains in normal and overweight subjects.

Acknowledgements We thank the Foundation Nutrition 2000Plus for financial support.

\section{References}

1. Mannix ET, Manfredi F, Farber MO (1999) Elevated $\mathrm{O}_{2}$ cost of ventilation contributes to tissue wasting in COPD. Chest 115:708-713

2. de Godoy I, Donahoe M, Calhoun WJ, Mancino J, Rogers RM (1996) Elevated TNF-alpha production by peripheral blood monocytes of weight- losing COPD patients. Am J Respir Crit Care Med 153:633-637

3. Saudny-Unterberger H, Martin JG, Gray-Donald K (1997) Impact of nutritional support on functional status during an acute exacerbation of chronic obstructive pulmonary disease. Am J Resp Crit Care Med 156:794-799

4. Ragsdale D (1987) Nutritional program for heart transplantation. J Heart Transplant 6:228-233

5. Hussaini SH, Oldroyd B, Stewart SP et al (1998) Effects of orthotopic liver transplantation on body composition. Liver 18:173-179

6. Probst M, Goris M, Vandereycken W, Van Coppenolle H (2001) Body composition of anorexia nervosa patients assessed by underwater weighing and skinfold-thickness measurements before and after weight gain. Am J Clin Nutr 73:190-197

7. Nindl BC, Friedl KE, Frykman PN, Marchitelli LJ, Shippee RL, Patton JF (1997) Physical performance and metabolic recovery among lean, healthy men following a prolonged energy deficit. Int J Sports Med 18:317-324

8. Keys A, Brozek J, Henschel A, Mickelsen O, Taylor HL (1950) The biology of human starvation. Minnesota Press, Minneapolis

9. Lukaski HC, Johnson PE, Bolonchuk WW, Lykken GL (1985) Assessment of fat-free mass using bioelectrical impedance measurements of the human body. Am J Clin Nutr 41:810-817

10. Gudivaka R, Schoeller D, Kushner RF (1996) Effects of skin temperature on multifrequency bioelectrical impdance analysis. J Appl Physiol 81:838-845

11. Kyle UG, Genton L, Karsegard L, Slosman DO, Pichard C (2001) Single prediction equation for bioelectrical impedance analysis in adults aged 20-94 yrs. Nutrition 17:248-253

12. Genton LC, Karsegard VL, Kyle UG et al (2001) Comparison of four bioelectrical impedance analysis formulas in healthy elderly adults. Gerontology 47:315-323

13. Kyle UG, Genton L, Mentha H, Nicod L, Slosman D, Pichard C (2001) Reliable bioelectrical impedance analysis estimate of fat-free mass in liver, lung and heart transplant patients. JPEN J Parent Enteral Nutr 25:45-51

14. Forbes GB (1992) Exercise and lean weight: the influence of body weight. Nutr Rev 50:157-161

15. Christie PM, Hill GL (1990) Return to normal body composition after ileoanal J-pouch anastomosis for ulcerative colitis. Dis Colon Rectum 33:584-586 